\title{
Journey from Measles to Modified Measles in Hilly State of Himachal Pradesh
}

\author{
Gupta SN ${ }^{1, *}$, Gupta Naveen², Gupta Shivani ${ }^{3}$ \\ ${ }^{1}$ District AIDS Project Officer, Chief Medical Officer office, Kangra at Dharamshala, Himachal Pradesh, India cum Epidemiologist in \\ Charge, District Chamba \\ ${ }^{2}$ Freelance researcher in Epidemiology and Ayurveda, Kangra, Himachal Pradesh, India \\ ${ }^{3}$ Free lance researcher in infectious diseases and food technology, Shoolini University, Solan, Himachal Pradesh \\ *Corresponding author: drsurendernikhil@yahoo.com
}

Received June 25, 2014; Revised August 09, 2014; Accepted August 13, 2014

\begin{abstract}
Background and aims: It is commonly observed that in many of the outbreak settings, more than one virus may be infecting the given population. In twin or triple outbreak of measles, german measles (rubella) and varicella in highly immunized hilly areas, maximal number of the case patients in all the hilly villages belonged to the older age group. It suggested an obvious shift to the higher age group, warranting second dose opportunity in such case scenario. The clinical presentations of viral diseases are too similar to differentiate. The aim is to categorize clearly the case patients of modified measles, rubella and atypical measles in outbreak settings. Discussion: Several solitary as well as mixed outbreaks of measles, german measles, chickenpox/herpes zoster have been investigated and documented. In many a time outbreak setting in the hilly areas of Himachal Pradesh, it is a matter of common observation that more than one virus are simultaneously infecting the population. On the basis of outbreak investigation and analytical inference, it has been observed that the symtomatology of modified measles and laboratory confirmed rubella case patients/epidemiologically linked cases are so similar placed that many a time, it becomes much difficult to line list the cases in one section of modified measles or rubella or atypical cases. Conclusion: Similarities of morphological symptoms between modified measles and rubella is the point of challenge and it causes debate between pediatrician and field epidemiologist to differentiate and classify them, thereby causing misleading of the meaning in the outbreak setttings.
\end{abstract}

Keywords: modified measles, rubella, twin outbreak, triple infection, Kangra, Northern Himachal

Cite This Article: Gupta SN, Gupta Naveen, and Gupta Shivani, “Journey from Measles to Modified Measles in Hilly State of Himachal Pradesh.” American Journal of Epidemiology and Infectious Disease, vol. 2, no. 4 (2014): 93-96. doi: 10.12691/ajeid-2-4-2.

\section{Background and Aims}

Measles, the vaccine preventable disease still issues the death warrant for low income group countries with weak infrastructure and 95\% of the death is reported from these countries. In India, measles mortality has been estimated to be 80,000 which contribute to nearly $4 \%$ for under five children [1] while rubella is a mild febrile rash illness in children and adolescence. Rubeola or Measles, one of the earliest recognized diseases, probably was not the significant problem before the building of the large cities. The name Rubeola is derived from Arabic, meaning thereby Red Spots [2] Charak (1800 B.C.) has described it under small pox which was named as Masurika. Madhava in $7^{\text {th }}$ century described it as derangement of Pitta and Kapha [3]. The earliest medical description was given by Rhazes in $9^{\text {th }}$ century in Bagdad (Black et al; 1977). It was Sydenham's published work in 1675 which differentiated measles from other exanthemas. Home established measles as an infectious disease in $18^{\text {th }}$ century. Another worker Withering in 1792 reasserted that the difference of measles with small pox existed. Recognition of the measles as a separate entity from German measles dates back to early $19^{\text {th }}$ century. Panum was the first worker who did classical studies on the epidemiology of measles in Faroe Island in 1847. Measles virus was isolated from eleven years old boy named David Edmonston in USA in 1954 (Enders et. Al: 1954). The Kopliks spots which are absolutely pathognomic of the invasion of the measles were described by Koplik in 1896 [4].

Measles immunization coverage in Himachal Pradesh ranges from $72 \%$ [5] to $89 \%$ [6] to $86 \%$ [7] which suggests that there is gradual rise over the years while in India it satisfactorily increased from $42 \%$ [8] to 51\% [9] to $59 \%$ [10]. Diseases reappear when immunization coverage drops. But in the country, Delhi state has higher vaccine coverage since it has taken the lead and initiative of the two dose schedule of measles and measles, mumps, rubella (MMR) at 9 months and at 15 months respectively. Goa, Maharashtra, and Tamil Nadu reached 84-88\% coverage. Six states, Andhra Pradesh, Chhatisgarh, Delhi, Gujarat, Punjab and Madhya Pradesh achieved coverage of more than 70 per cent [11]. As the coverage increases, inter epidemic interval increases as well as focus shifts 
towards older age groups as observed as in Thailand and Kangra [12]. The effective vaccination has reduced the incidence in children and the adolescent groups are affected. Higher vaccination coverage has led to widening of the outbreak intervals and in the outbreak settings, more and more of case patients of measles, rubella and chickenpox are now being examined in higher age groups as have been observed in the outbreak patterns on Kangra district of northern Himanchal of India. More than one viruses have also been recorded in the one outbreak, be it measles and rubella; measles, rubella and varicella/herpes zoster $[13,14,15,16]$. Clinician in chamber and field epidemiologist contests their claim differently for these viral diseases depending upon the morphological similarities of symptomatology and their fleeting nature within one to two days. This sparks the strong point of debate. The aim is to categorize clearly the case patients of modified measles, rubella and atypical measles in outbreak settings. Measles, modified measles, rubella and atypical measles are case defined. Measles is defined clinically by WHO criteria as the occurrence of a febrile rash with or without cough, coryza and conjunctivitis while modified measles means measles in individuals with vaccine induced (but limited) immunity. Rubella means a short febrile rash while atypical measles has the characteristic erythematous, maculopapular rash which it progresses frequently to vesicular, petechial, or purpuric lesions. A debate paper of modified measles versus rubella is being reported here for its rarity and clinical importance.

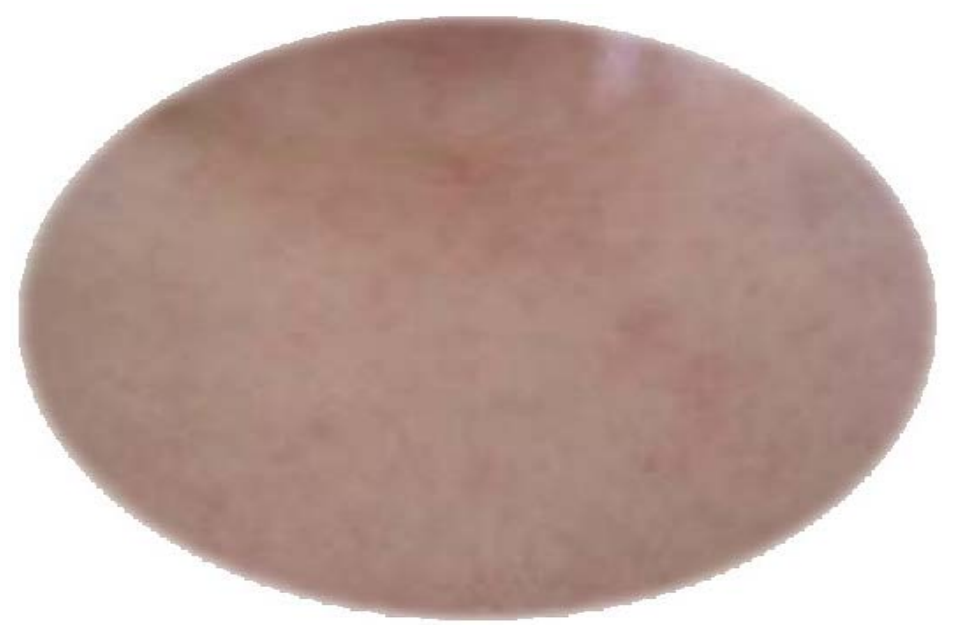

Figure 1. Fleeting maculopapular skin rash on the chest of a case patient

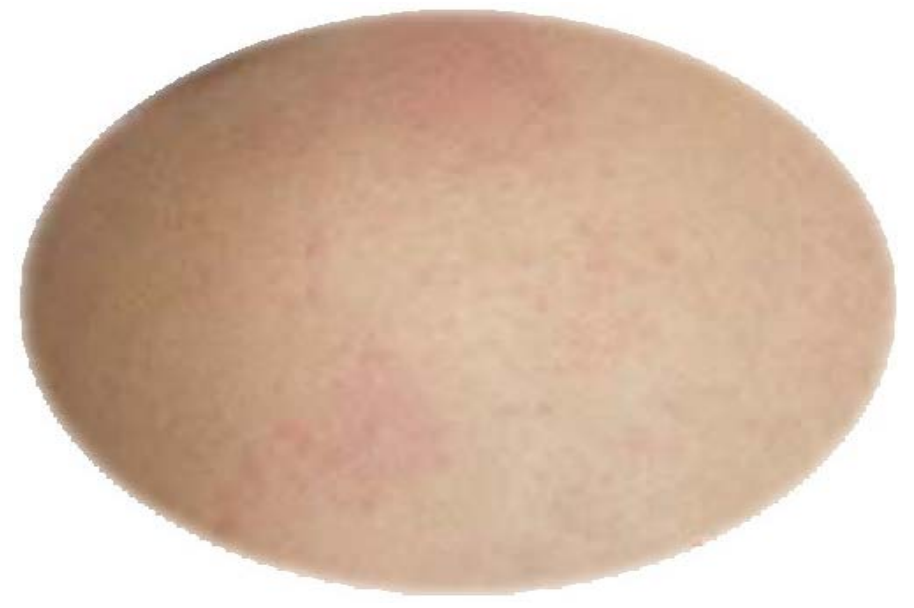

Figure 2. Fleeting maculopapular skin rash on theback

\section{Results and Discussion}

In India, states like Himachal Pradesh have achieved the high coverage of measles, a notifiable disease under universal immunization program but not rubella and hence, no national control programme and no programme based vaccination. Many solitary as well as mixed outbreaks of measles, german measles, chickenpox/herpes zoster have been investigated and documented. In the outbreak settings, it is a matter of common observation that more than one virus are simultaneously infecting the population. In 2006, in Double infection of measles/german measles
[13]........, we initiated investigation on the suspected outbreak of measles (febrile rash) to confirm diagnosis and formulate recommendations for prevention and control. Sixty case patients were identified from 1026 people in 5 villages. Of these, 41 were diagnosed by clinically, 8 were laboratory confirmed as measles and 11 were epidemiologically linked german measles case patients. $70 \%$ of the cases were vaccinated for measles, none for german measles. Out of the eight laboratory confirmed case patients, five had got previous measles vaccination. Prima facie, the clinical presentations of both rubella and modified measles were difficult to differentiate. The clinical features were fast to appear and 
then disappear quickly while results reported by laboratory were plus/minus for some of the case patients, thereby creating an obvious difficulty for understanding them.

Second round of mixed outbreak of measles and chickenpox in 2007 twin outbreak involved three hilly villages of Northern Himachal. Initially, we investigated this propagated outbreak-Epidemiological investigation of mixed outbreaks of measles/varicella [14]..... on the suspicion of measles but the epidemiologically linked sporadic confirmed case patients of varicella were also examined concurrently on the symptoms of maculopapulovesicular rash. We identified 29/35 measles and 6/35 were confirmed as epidemiologically linked unvaccinated chickenpox case patients. The rash was atypical in appearance (maculopapular with few or no vesicles) in case patients. Although the severity of symptoms was mild in nature in varicella cases, yet in twin outbreak the case patients of measles were full blown while those of concurrent varicella were subdued. Therefore, apparently, there was no point of debate for varicella case patients' throughout, but on other hand, clinically the cases belonged to varicella but laboratory results rejected the clinical findings disfavoring the measles morphology and epidemiology, a point of strong debate. Three case patients of atypical measles with maculopapular rash leading to vesicular stage vis a vis varicella were observed. They were immunized against measles. The proportion of the children vaccinated was 95\% for measles but nil for varicella. Case patients were morphologically so closely situated that, it becomes enormously difficult to list out the cases in either in one section of measles or modified measles or rubella.

In the third set of outbreak in 2007, German measles outbreak bursts in two unvaccinated border [15] .........., we identified 116 cases in eight villages (112/116 clinically and 04/116 laboratory confirmed) Majority of cases were immunized against measles, but only minor cases for rubella. The laboratory confirmed four case patients of rubella (german measles) had previous shots of measles vaccination. Here in this outbreak, we initiated investigation on the suspected outbreak of measles (febrile rash) to confirm diagnosis and formulate recommendations for prevention and control but later on, the results of laboratory forced us to revise the diagnosis in favour of german measles.

In the fourth scenario of outbreak in 2009, Concurrent multiple outbreaks of varicella/rubeola/ german measles in unvaccinated children of co-educational Mount Carmel Senior Secondary School [16]....... we identified 505 case patients from mixed outbreaks of varicella, measles and rubella (30/505 clinically, 467/505 epidemiologically linked and 8/505 laboratory confirmed case patients from a study population of 3280 . We investigated the suspected outbreak with case definition of varicella but measles 20/3280 (0.60\%) and rubella 34/3280 (1.03\%) cases were also observed. 5/10 samples for IgM antibodies for chickenpox and 2/10 samples were positive for rubella. Vaccination for measles was 93\%; $2 \%$ for rubella as MMR and 5\% for varicella. Two confirmed cases of rubella have been previously immunized against measles. Due to the intervention of the laboratory results, the clinical presentations of both rubella and modified measles with fleeting maculopapular rash confused the situation in the setting which sparked off the points of high debate between epidemiologist of public health and clinician in sitting in chamber. Both contested their claims in their own ways.

In all the four outbreaks, one or more than one virus is infecting the population. It was crystal clearly observed and subsequently, based upon the presenting complaints, debate ensued among the colleagues for proper diagnosis and classification of these viral diseases. Mild febrile rashes were present both in german measles (rubella) and measles. Symptomatogy in both the cases is morphologically so similar and maculopapular rash was so fleeting that it disappears in one to two days and to add confusion, the ELISA for both the results are sometimes, both ways (+/_). Then what? In all above mentioned outbreaks, majority of the case patients in all the hilly villages belonged to the older age group (11-20 years), suggesting an obvious shift to the higher age group. This suggests waning of immunity with age. In addition to this, as the vaccine efficacy for measles is only $85 \%$ for first dose of measles at nine completed months, there is progressive accumulation of a small number of susceptible children in the community over the years. Such accumulations are typically caused by the combination of the measles vaccine efficacy that does not reach $100 \%$ and children left un-immunized each year. As the coverage increases, inter-epidemic interval increases as well as a shift towards older age groups may be observed as in Kangra [12,13,15,16].

We have investigated many of such outbreaks in field settings; either they are two in one (measles and rubella/or measles and chickenpox); or three in one (measles, rubella and varicella). Modified measles is a distinct clinical entity characterized by less intense symptoms and a milder rash which may occur in individuals with pre-existing partial immunity induced by active or passive vaccination [17]. Such cases have also been labeled as modified measles among health care professionals in the literature [18]. But based upon analytical studies and field observation, the symtomatology of modified measles and laboratory confirmed rubella case patients/epidemiologically linked cases are so similar that in most of the times, it gets extremely difficult to diagnose the cases in one group; modified measles or rubella or atypical cases. There is obvious point of conflict between clinician in the chamber and epidemiologist reporting from the field.

In conclusion, modified measles versus rubella can occur concurrently in one outbreak setting and we need to be differentiating between modified measles and rubella case patients which are, at times a difficult task. Further research is needed to discover more of truth.

\section{References}

[1] Black RE, Cousens S, JohnsonHL, Lawn JE, Rudan I, Bassani DG et al; child Health Epidemiology Reference Group of Who and UNICEF Global, regional and national causes of child mortality In 2008: A systematic analysis, lancet 2010;375: 1969-87.

[2] Maxy K.F.Rosenau Preventive Medicine and Public Health, New York Appleton Century Crafts, 1956, p 25-35.

[3] Pandey M.P. Pandey, Pandey A. A Treatise of Principles and Practice of Ayurvedic Medicine, New Delhi. Shanti Publication, 1983, p 499-518.

[4] Morley D.C. Measles in Nigeria. Amer J Dis. Child 1999. 
[5] National Family Health Survey-1, Key Indicators for Himachal Pradesh, 1992-93, India. (hetv.org > India; last accessed on $14^{\text {th }}$ Oct2013).

[6] National Family Health Survey-2, Key Indicators for Himachal Pradesh, 1998-99, India.

(www.measuredhs.com/pubs/pdf/SR81/SR81.pdf; last accessed on $15^{\text {th }}$ Oct2013).

[7] National Family Health Survey-3, Key Indicators for Himachal Pradesh, 2005-06, India.

(www.measuredhs.com/pubs/pdf/FRIND3/FRIND3-VOL2.pdf; last accessed on $14^{\text {th }}$ Sept2013.

[8] National Family Health Survey-1, Key Indicators for India, 199293, India (www.measuredhs.com/pubs/pdf/FRIND1/FRIND1.pdf; last accessed on $14^{\text {th }}$ Dec2013).

[9] National Family Health Survey-2, Key Indicators for India, 199899, India. (www.measuredhs.com/pubs/pdf/SR81/SR81.pdf; last accessed on $14^{\text {th }}$ Sept2013).

[10] National Family Health Survey-3, Key Indicators for India, 200506, India. (www.measuredhs.com/pubs/pdf/FRIND3/FRIND3VOL2.pdf; last accessed on $14^{\text {th }}$ Sept2013).

[11] Anita Chakravarti, Measles control: Current trends \& recommendations; Indian J Med Res 121, February 2005, pp 7376.

[12] Gupta SN, Gupta N. Two highly immunized hilly areas versus double measles outbreak investigations in district Kangra, Himachal Pradesh, India, in 2006. J Global Infect Dis 2009; 1:1420.
[13] SN Gupta, N Gupta, NS Neki; Double infection of measles/german measles in district Kangra of Northern India; presented as poster in the Seventh TEPHINET Global Conference Amman, Jordan, 10-15 Nov 2012 and published in OSIR, 2013.

[14] Gupta SN, Gupta Naveen, Gupta Shivani; Epidemiological investigation of mixed outbreaks of measles/varicella in hilly villages of district Kangra, Himachal Pradesh, India; Vol. 2, issue 2; Global Journal Of Medicine And Public Health; 2013.

[15] Gupta SN, Gupta N, Neki NS. German measles outbreak bursts in two unvaccinated border hilly districts of Northern Himachal Pradesh, India.Ann Trop Med Public Health 2012; 5:219-24.

[16] Gupta SN and Gupta N; Concurrent multiple outbreaks of varicella/rubeola/ german measles in unvaccinated children of coeducational Mount Carmel Senior Secondary School, Thakurdwara-Palampur of Northern Himachal, 2009; International Meeting on Emerging Diseases and Surveillance: IMED 2013; Vienna, Austria.

[17] Patro BK, Shewade HD, Kathirvel S, Senjam SS, Singh MP, Ratho R K. Outbreak of "Modified measles" in an urban resettlement colony of North India. Indian J Public Health, 2012; 56:168-9.

[18] Rota JS, Hickman CJ, Sowers SB, Rota PA, Mercader S, Bellini WJ. Two case studies of modified measles in vaccinated physicians exposed to primary measles cases: High risk of infection but low risk of transmission. J Infect Dis 2011; 204; 1: S559-63. 